\title{
Philippe BORGEAUd, Sara PETRELla, Le singe de l'autre. Du sauvage américain à l'histoire comparée des religions
}

Genève-Paris, Bibliothèque de Genève/Éditions des Cendres, 2016, 123 p., Illustrations, index.

\section{Carmen Bernand}

\section{(2) OpenEdition} Journals

Édition électronique

URL : https://journals.openedition.org/assr/44579

DOI : $10.4000 /$ assr.44579

ISSN : $1777-5825$

Éditeur

Éditions de l'EHESS

Édition imprimée

Date de publication : 1 décembre 2018

Pagination : 202-203

ISSN : 0335-5985

\section{Référence électronique}

Carmen Bernand, «Philippe borgeaud, Sara petrella, Le singe de l'autre. Du sauvage américain à I'histoire comparée des religions ", Archives de sciences sociales des religions [En ligne], 184 | octobredécembre 2018, mis en ligne le 01 décembre 2018, consulté le 12 janvier 2022. URL : http:// journals.openedition.org/assr/44579; DOI : https://doi.org/10.4000/assr.44579

Ce document a été généré automatiquement le 12 janvier 2022.

(c) Archives de sciences sociales des religions 


\section{Philippe BORGEAUD, Sara PETRELLA, Le singe de l'autre. Du sauvage américain à l'histoire comparée des religions}

Genève-Paris, Bibliothèque de Genève/Éditions des Cendres, 2016, 123 p., Illustrations, index.

Carmen Bernand

\section{RÉFÉRENCE}

Philippe BORGEAUD, Sara PETRELLA, Le singe de l'autre. Du sauvage américain à l'histoire comparée des religions, Genève-Paris, Bibliothèque de Genève/Éditions des Cendres, 2016, 123 p., Illustrations, index.

1 Ce livre, beau et stimulant, a été écrit à quatre mains, par un spécialiste de l'histoire des religions et une historienne de l'art. Il porte principalement sur la comparaison de deux ouvrages publiés autour de 1724 : les Mœurs des sauvages américains comparées aux mœurs des premiers temps, du Père jésuite Lafitau et les Cérémonies et coutumes religieuses de tous les peuples du monde, édités par Bernard à Amsterdam en 1723. Le Père Lafitau est devenu un chroniqueur incontournable pour l'histoire des peuples indigènes de la Nouvelle-France. Le nom de Bernard, moins connu, réunit deux auteurs : Jean-Frédéric Bernard et Bernard Picart, graveur. Lafitau est catholique, les deux Bernard agissant de concert sont protestants, et cette différence explique leurs positions respectives à l'égard des idolâtries. Tous utilisent l'iconographie à des fins didactiques et idéologiques. Les images ont une histoire commune qui remonte au xvI siècle, et que chacun des auteurs reprend avec des variantes. Enfin, le texte de Borgeaud et de Petrella est très documenté ; les notes, érudites et claires, proposent de nouvelles 
questions et l'iconographie, très bien reproduite, nous apprend beaucoup sur les graveurs, leur place dans les arts et leur influence esthétique et politique.

Les deux œuvres de référence, qui se déploient sur plusieurs volumes, apparaissent dans le contexte historique des Lumières, une époque où le regard sur la croyance est marqué par la critique et le scepticisme, annonciateurs de la sécularisation. L'altérité des " primitifs » est vue sous l'angle de la relativité des cultures, mais celle-ci est posée de façon différente par le catholique Lafitau et par Bernard le protestant. Dès le début, Borgeaud et Petrella introduisent leurs différentes perspectives, en comparant les deux frontispices placés au début de leurs sommes. Celui de Lafitau, orné de figures diverses dont le sens sera éclairé dans le courant de l'argumentation des auteurs de ce livre, place la diversité des croyances comme des variantes chrétiennes d'une même origine religieuse symbolisée par l'Arbre de Vie flanqué d'Adam et d'Ève. En revanche, la gravure initiale de Bernard a pour objet de montrer l'universalité de la superstition, partagée par les anciens et primitifs, les mahométans, sur la partie inférieure, et les catholiques. Au centre de la gravure, une femme coiffée de la tiare papale tient un rameau d'olivier autour duquel se tortille une couleuvre (p. 102-103). L'arbre de la connaissance occupe tout le côté gauche, à l'ombre duquel on distingue les dix commandements (version de la Septante), mais malgré sa dimension majestueuse, il ne semble concerner que le peuple juif. Dans le lointain - car les primitifs sont aussi des gens « antiques»-, on distingue nettement le culte au veau d'or, une pyramide maya, le dieu solaire de la Floride, la statue d'une divinité hindoue aux multiples bras (Parvati ?) et diverses pagodes fantaisistes.

3 Si Lafitau est bien connu des historiens et des anthropologues, Jean-Frédéric Bernard, fils d'un pasteur huguenot de Provence, apparaît rarement mentionné par les américanistes. Ses Réflexions morales, satiriques et comiques (1711) annoncent les Lettres persanes. Parmi d'autres ouvrages, le plus important est celui sur les Cérémonies, illustrées par Bernard Picart, un catholique passé à l'Église réformée. L'histoire complexe de ce texte, joyau de la Bibliothèque de Genève, est retracée dans les pages 37-54 et explique le titre du livre recensé ici. Selon Bernard, toutes les religions, hormis celles où l'on reconnaît "les caractères de révélation", marchent d'un même pas, « un peuple est le singe de l'autre ». On peut appeler ces dieux de divers noms, car cette confusion a été provoquée, voire voulue par "l'infinité des vicaires de la divinité ». La source de l'idolâtrie réside dans la nature humaine et non pas dans les ruses du diable. Bernard est également intéressé par le peuplement de l'Amérique, qui n'a pu se faire que depuis la Tartarie. Il rejoint ainsi les spéculations de jésuites du XVI siècle comme José de Acosta. Il n'est pas étonnant qu'il ne mentionne pas l'existence d'un passage maritime, puisque le détroit de Bering n'a été découvert (par les Européens) qu'en 1741.

4 La seconde partie, «Images en parallèle » traite de l'iconographie. Il est difficile d'en rendre compte, tant la démonstration est tributaire de la documentation. Cette analyse, passionnante, montre l'importance des gravures de Théodore de Bry dans la constitution de la figure canonique de l'Indien américain et de la persistance (avec des variantes) de certains thèmes comme celui du serpent, si évocateur pour les chrétiens, et des rondes de danseurs. Ces derniers perdent leur altérité initiale au xvIII ${ }^{\mathrm{e}}$ siècle, comme ces jeunes filles éthérées évoluant gracieusement devant un temple funéraire d'Amérique du Nord, qui illustrent un passage des Mœurs de Lafitau. Signalons que la danse des sauvages, altérée par le "commerce des Européens»(p.108) mais si 
importante chez ces peuples, connaîtra au XVIII ${ }^{\mathrm{e}}$ siècle un succès éclatant en France, puis ailleurs, grâce aux Indes Galantes de Rameau. Bien avant, dans la culture baroque des jésuites, les spectacles musicaux représentés par les indigènes, sous le regard des prêtres, avaient déjà dilué l'altérité dans l'esthétique artistique. 